\title{
Extended Right Hepatectomy with caudate lobe resection using the hilar "en bloc" resection technique with a modified hanging maneuver
}

\author{
Running head: Hanging in hilar cholangio \\ Perini MV1,2, Coelho FF¹, Kruger JA ${ }^{1}$, Rocha F³ , Herman $\mathrm{P}^{1}$
}

1- Digestive Surgery Division, Department of Gastroenterology, University of Sao Paulo Medical School, Sao Paulo, SP, Brazil

2- Department of Surgery, Austin Hospital, University of Melbourne, Melbourne, Victoria, Australia

3- Section of General, Thoracic and Vascular Surgery, Department of Surgery, Digestive Disease Institute, Virginia Mason Medical Center, Seattle, WA, USA

Perini, MV MD, PhD
Coelho, FF MD, PhD
Kruger, JA MD
Rocha, F MD
Herman, P MD, PhD

Corresponding Author:

Marcos Vinicius Perini, MD, PhD

Department of Surgery - University of Melbourne

145 Studley Road, Lance Townsend Building, lvl 8

Heidelberg, Australia 3084

Phone: + 6194963670

Email: marcos.perini@unimelb.edu.au

Abstract

The hanging liver maneuver is a useful technique to guide the transection of 
liver parenchyma by lifting a tape passed between the anterior surface of the inferior vena cava and the liver. Modified hanging liver maneuvers have been described in different types of liver resection. Surgical resection of hilar cholangiocarcinoma can involve the portal vein and the caudate lobe for margin clearance. However, hilar dissection and resection of the caudate lobe can be a challenging during the hanging maneuver once the tape is positioned.

Here in we describe a modified hanging liver maneuver for a hilar 'en bloc' extended right hepatectomy with portal vein resection for the treatment of hilar cholangiocarcinoma including the caudate lobe.

Key words: hepatectomy, cholangiocarcinoma, vascular resection, technique, surgery

1- Introduction

Extended right hepatectomy with caudate lobe resection is the treatment of choice for hilar cholangiocarcinoma arising in the biliary bifurcation with extension to the right side of the liver[1-3]. In cases where the tumour is invading the portal vein, vascular resection is mandatory in order to achieve an R0 resection [4].

Given the incidence of positive margins during resection of hilar cholangiocarcinoma resection previous groups have proposed a 'hilar en bloc resection technique' [5]. It consists of performing the biliary and the hepatic arterial/venous dissection away from the tumour followed by transection of the liver so that the specimen is only attached by the portal vein. The bile duct is then divided and the portal vein is controlled and resected with the tumour in situ. The specimen is then removed and portal venous reconstruction is performed. This strategy avoids dissection in the vicinity of the tumour to achieve a wider margin.

The hanging liver maneuver (HLM) is a technique used in order to facilitate 
the anterior approach while avoiding liver mobilization[6]. It consists of passing a tape between the anterior surface of the inferior vena cava (IVC) and the liver parenchyma through the right (RHV) and middle hepatic veins (MHV) in order to lift the liver. This maneuver is useful to guide the transection plane, allowing for control of bleeding in the deeper parenchyma while protecting the anterior surface of the IVC [7-9].

Herein we describe a modified hanging maneuver for extended "en bloc" right hepatectomy with caudate lobe resection and portal vein reconstruction with hilar cholangiocarcinoma.

\section{2- Surgical technique}

A reversal L shape incision (upper median plus right-sided sub costal transverse incision) is performed in a supine position. The falciform ligament is divided to expose the hepatic veins and the anterior surface of the vena cava. The space between the right hepatic vein and the common trunk of middle/left bluntly dissected using a right-angled clamp (Couinaud's space). The short hepatic veins from the caudate lobe to the inferior vena cava are divided and the right and left hemi-livers are fully mobilized from their attachments. In order to achieve a better exposure, Arantius ligament is divide. Care should be taken if the left hepatic artery arises from the left gastric artery.

A small rubber band tube (14-F size) is passed behind the liver between the right and middle/left hepatic veins (Couinaud's space) into the retro hepatic space keeping the distal inferior tip anterior to the caudate lobe, as shown on Figure 1. In a minority of patients, it is possible to create a plan between the left and middle hepatic veins; and if that is possible the tape, after positioning between the right and middle/left trunk, is repositioned

Figure 1 
After hilar lymphadenectomy, portal dissection is performed as described by Neuhaus et al.. Briefly, the proper hepatic artery is isolated at the left border of the hepatoduodenal ligament and the right hepatic artery is divided immediately at its origin. After division of the supra pancreatic bile duct, frozen section is performed. The main portal vein is dissected as well as the left branch of the portal vein within the umbilical fissure, with careful ligation of caudate lobe and segment IV branches. Left portal vein and bile duct are exposed close to the round ligament insertion into the left portal vein, in a non-tumour area. When the tape is pulled anteriorly and caudally, the caudate lobe is usually left hanging anteriorly or to the left side of the tape. It is important to make sure that the caudate lobe is then rotated to the right side of the tape, in order to leave it encircling the left lateral sector and passing close to the Arantius ligament, previously divide (Figure 2).

\section{Figure 2}

Using a right angle clamp the distal end of the tape is passed between the left portal vein and the left biliary tree, leaving the left portal vein outside the hanging maneuver (ventral side of the hilar plate) (Figure 3, 4 and 5).

\section{Figure 3}

\section{Figure 4}

\section{Figure 5}

If the tape is inserted between the right and the middle/left venous trunk, the middle hepatic vein will be found when performing liver transection. If the tape is inserted between the left and middle hepatic vein, there will a portion of liver tissue that will not be transected and will contain the middle hepatic vein. Whenever possible we prefer to relocate the tape between the middle and left hepatic veins.

Transection is performed using CUSA and bipolar forceps and major vessels are ligated until the specimen will be attached to the remnant liver only by the 
portal vein and the bile duct (Figure 6). At this point, the bile duct is sectioned and sent for frozen analysis.

Figure 6

Meanwhile, vascular clamps are applied in the main portal vein and the left portal vein branch that are sectioned (Figure 7). Right hepatic vein trunk is divided under vascular clamps and running suture of 4.0 Prolene ${ }^{\circledR}$ is applied in the caval end. Specimen is retrieved and left bile duct is sent for frozen section. End-to-end portal vein anastomosis is performed using running 6.0 Prolene ${ }^{\circledR}$ sutures (Figure 8). Roux en $Y$ biliary anastomosis is finally performed and intra operative doppler is done to make sure that portal anastomosis is patent. If frozen section is positive, extending bile duct resection can be performed. In some cases, bile ducts to segments 2 and 3 will be found and two hepatico-jejunostomies will be necessaries.

Figure 7

Figure 8

Table 1 illustrates the demographics, operative data and outcome of the patients submitted to this technique.

Table 1

\section{3- Discussion}

In patients with hilar cholangiocarcinoma, a major hepatectomy with removal of the caudate lobe is usually indicated for an oncologically sound resection. Many centers have reported that a tumour free margin is critical for a curative resection [10-12]. This type of resection can be associated with high blood loss due to the need for division of large areas of liver parenchyma and major vascular structures. The presence of a tape to hang the liver can serve as a guide for transection of a plane between the left lateral section and the remaining liver[13].

Although the hanging liver maneuver was developed to facilitate a transection plane without liver manipulation, it can also be applied in resections in which a full mobilization is done. It is especially useful when a lack of landmarks 
during parenchymal transection can cause massive bleeding [3]. In addition, during extended hepatectomies requiring dissection close to major hepatic vessels there is significant potential for vascular injuries $[14,15]$.

Our technique for extended right hepatectomy with caudate lobe resection using the hanging liver maneuver and the hilar "en bloc" resection is a simple and feasible technique that can be useful during liver transection. It adds to the "non touch approach" an easier and useful tool during parenchymal section, as the cross sectional line offered by pulling the hanging tape leads to a straight plane to be followed. Besides that, by dissection the left portal vein far away from the tumour, the oncological principals are respected what increases the chances of an R0 resection.

Following liver mobilization, the caudate lobe should be rotated to the right and the tape relocated to the Arantius' sulcus, allowing for compression of the liver parenchyma. Should an injury occur to the MHV, bleeding can be controlled by compressing the parenchyma in the hanging liver remnant (pulling the tape against the assistant pushing fingers).

By pulling the tape cranially, the resected liver parenchyma is compressed and as transection plane deepens within the parenchyma, anterior compression can be applied to minimize bleeding. In select circumstances, a vessel loop can be used to encircle the left main trunk (if possible) and be clamped if a major vein injury occurs [16-18].

Care should be taken not to damage the left portal vein after bile duct transection when applying the hanging liver maneuver, as the tape, if pushed caudally, can tear the vein. To avoid this type of injury, the ends of the tape are tied together and only moved cephalad to avoid tearing the portal vein and malleable tapes (Penrose drains, rubber band) are preferred over the more stiffs ones (nasogastric tubes). 
4- Conclusion

During extended right hepatectomy and caudate resection for patients with hilar cholangiocarcinoma and portal vein invasion, the use of a modified hanging liver maneuver can be a useful tool for an en bloc resection of the tumour with negative margins while minimizing the potential for blood loss.

$5-$

\section{References}

1. Jonas S, Benckert C, Thelen A, et al.: Radical surgery for hilar cholangiocarcinoma. Eur J Surg Oncol 2008;34:263-271.

2. Neuhaus P, Jonas S, Bechstein WO, et al.: Extended resections for hilar cholangiocarcinoma. Ann Surg 1999;230:808-818; discussion 819.

3. Igami $\mathrm{T}$, Nishio $\mathrm{H}$, Ebata $\mathrm{T}$, et al.: Surgical treatment of hilar cholangiocarcinoma in the "new era": the Nagoya University experience. J Hepatobiliary Pancreat Sci 2010;17:449-454.

4. Ebata T, Nagino M, Kamiya J, et al.: Hepatectomy with portal vein resection for hilar cholangiocarcinoma: audit of 52 consecutive cases. Ann Surg 2003;238:720-727.

5. Neuhaus $\mathrm{P}$, Thelen A, Jonas S, et al.: Oncological superiority of hilar en bloc resection for the treatment of hilar cholangiocarcinoma. Ann Surg Oncol 2012;19:1602-1608.

6. Belghiti J, Guevara OA, Noun $\mathrm{R}$, et al.: Liver hanging maneuver: a safe approach to right hepatectomy without liver mobilization. J Am Coll Surg 2001;193:109-111.

7. Kokudo N, Sugawara Y, Imamura H, et al.: Sling suspension of the liver in donor operation: a gradual tape-repositioning technique. Transplantation 2003;76:803-807.

8. Imura S, Shimada M, Utsunomiya $\mathrm{T}$, et al.: A modified liver-hanging maneuver focusing on the ligamentum venosum for left hepatic lobectomy. Surg Today 2012;42:720-723.

9. Gaujoux S, Douard R, Ettorre GM, et al.: Liver hanging maneuver: an anatomic and clinical review. Am J Surg 2007;193:488-492.

10. Nagino M, Kamiya J, Arai T, et al.: "Anatomic" right hepatic trisectionectomy (extended right hepatectomy) with caudate lobectomy for hilar cholangiocarcinoma. Ann Surg 2006;243:28-32. 
11. D'Angelica MI, Jarnagin WR, Blumgart LH: Resectable hilar cholangiocarcinoma: surgical treatment and long-term outcome. Surg Today 2004;34:885-890.

12. Rocha FG, Matsuo K, Blumgart LH, Jarnagin WR: Hilar cholangiocarcinoma: the Memorial Sloan-Kettering Cancer Center experience. J Hepatobiliary Pancreat Sci 2010;17:490-496.

13. Nagino M, Kamiya J, Uesaka K, et al.: Complications of hepatectomy for hilar cholangiocarcinoma. World J Surg 2001;25:1277-1283.

14. Nanashima A, Sumida $\mathrm{Y}$, Abo $\mathrm{T}$, et al.: Trisectionectomy for large hepatocellular carcinoma using the liver hanging maneuver. Eur J Surg Oncol 2009;35:326-330.

15. Nanashima A, Tobinaga S, Abo T, et al.: Extended right hepatectomy for hilar bile duct carcinoma using the modified liver hanging maneuver. Hepatogastroenterology 2012;59:1583-1585.

16. Hwang S, Kim KH, Kim DY, et al.: Anomalous hepatic vein anatomy of left lateral section grafts and customized unification venoplasty for pediatric living donor liver transplantation. Liver Transpl 2013;19:184-190.

17. Peschaud F, Laforest A, Allard MA, et al.: Can the left hepatic vein always be safely selectively clamped during hepatectomy? The contribution of anatomy. Surg Radiol Anat 2009;31:657-663.

18. Dahmane R, Morjane A, Ravnik D, Hribernik M: Anatomy of the ligamentum venosum arantii and its contribution to the left hepatic vein and common trunk control. A study on cadaveric livers. Cells Tissues Organs 2009;190:297-300.

Acknowledgement in memorian: the authors are in debt with Mr Marcos Retzer for the illustrations and friendship throughout the years. The Department of Gastroenterology at the University of Sao Paulo Medical School misses him.

Figure 1: The tape is placed between IVC and the posterior aspect of liver; superiorly it is located between the right and middle hepatic veins and inferiorly, behind the caudate lobe of the liver. RHV: right hepatic vein. MHV: middle hepatic vein. LHV: left hepatic vein. CL: caudate lobe.

Figure 2: The caudate lobe that was in front of the tape is then rotated to the right side of the tape, in order to leave it encircling the left lateral lobe. It englobes the left main hilar structures and the liver parenchyma. RHV: right hepatic vein. MHV: middle hepatic vein. LHV: left hepatic vein. CL: caudate lobe. LPV: left portal vein. LBD: left bile duct. 
Figure 3: A right angle clamp is gently placed between the left biliary tree and the left portal vein after exposure of the left portal vein distally to the tumour. CL: caudate lobe. LPV: left portal vein. LBD: left bile duct.

Figure 4: The distal tape tip is then grasped with the right angle and is gently pulled and placed between the left portal vein and left biliary tree. Care should be taken not to damage the left portal vein. CL: caudate lobe. LPV: left portal vein. LBD: left bile duct.

Figure 5: The tape is now lifting liver parenchyma and the left biliary system. The liver in then pulled up and parenchymal transection is started. CL: caudate lobe. LPV: left portal vein. LBD: left bile duct.

Figure 6: After liver transection and left bile duct division, portal vein clamps are applied proximally (main portal vein) and distally (left portal vein). Main and left portal veins are divided (making sure a free margin achieved) and specimen is retrieved en bloc after the right hepatic vein is divided and oversewn. Bile duct margin is sent for frozen section at this stage. . RHV: right hepatic vein. MHV: middle hepatic vein. LHV: left hepatic vein. LPV: left portal vein. LBD: left bile duct.

Figure 7: Once the specimen is removed, the proximal (main) and distal (left) portal veins previously clamped are prepared for the anastomosis. In order to avoid kinging, extra-length is resected and the anastomosis is preferably done close to the liver parenchyma in a straight position. LPV: left portal vein. LBD: left bile duct. MPV: main portal vein.

Figure 8: End-to-end running veno-venous anastomosis is performed with 6.0 Prolene ${ }^{\circledR}$.After the portal vein is anastomosed, biliary reconstruction will be performed once frozen section result is back. LPV: left portal vein. LBD: left bile duct. MPV: main portal vein.

\section{Extended Right Hepatectomy with caudate lobe resection using the hilar "en bloc" resection technique with a modified hanging maneuver}




\section{Perini MV1,2, Coelho FF¹, Kruger JA ${ }^{1}$, Rocha F³, Herman $\mathrm{P}^{1}$}

Table 1 - Demographics, surgical record and outcomes of patients with hilar cholangiocarcinoma (CC) submitted to extended right hemi-hepatectomy with caudate lobe resection and portal vein reconstruction

\begin{tabular}{|l|l|l|l|l|l|l|l|l|l|l|}
\hline Patient & Sex & Age & $\begin{array}{l}\text { Op time } \\
\text { (min) }\end{array}$ & $\begin{array}{l}\text { Blood } \\
\text { tx }\end{array}$ & $\begin{array}{l}\text { Post op } \\
\text { complic }\end{array}$ & $\begin{array}{l}\text { DC } \\
\text { Grade }\end{array}$ & $\begin{array}{l}\text { LOS } \\
\text { (d) }\end{array}$ & Margin & $\begin{array}{l}\text { FU } \\
\text { (m) }\end{array}$ & Recur \\
\hline $\mathbf{1}$ & F & 67 & 600 & 2 & $\begin{array}{l}\text { Wound } \\
\text { infection }\end{array}$ & I & 9 & Neg & 24 & No \\
\hline $\mathbf{2}$ & M & 51 & 520 & 0 & Bile leak & II & 10 & Neg & 20 & No \\
\hline $\mathbf{3}$ & M & 65 & 620 & 2 & $\begin{array}{l}\text { Partial PV } \\
\text { thrombosi } \\
\text { s }\end{array}$ & IIIa & 21 & Neg & 18 & No* \\
\hline $\mathbf{4}$ & M & 68 & 610 & 0 & None & II & 9 & Neg & 22 & No \\
\hline $\mathbf{5}$ & M & 52 & 580 & 1 & None & I & 8 & Neg & 19 & No \\
\hline
\end{tabular}

Op. time $=$ operative time, Blood tx=intra-operative blood transfusion, Post op. complic= postoperative complications, DC Grade= Dindo-Clavien Grade, LOS= length of hospital stay, $\mathrm{FU}=$ follow up, Recur= tumour recurrence, ${ }^{*}=$ patient died 18 months after surgery from another cause. 


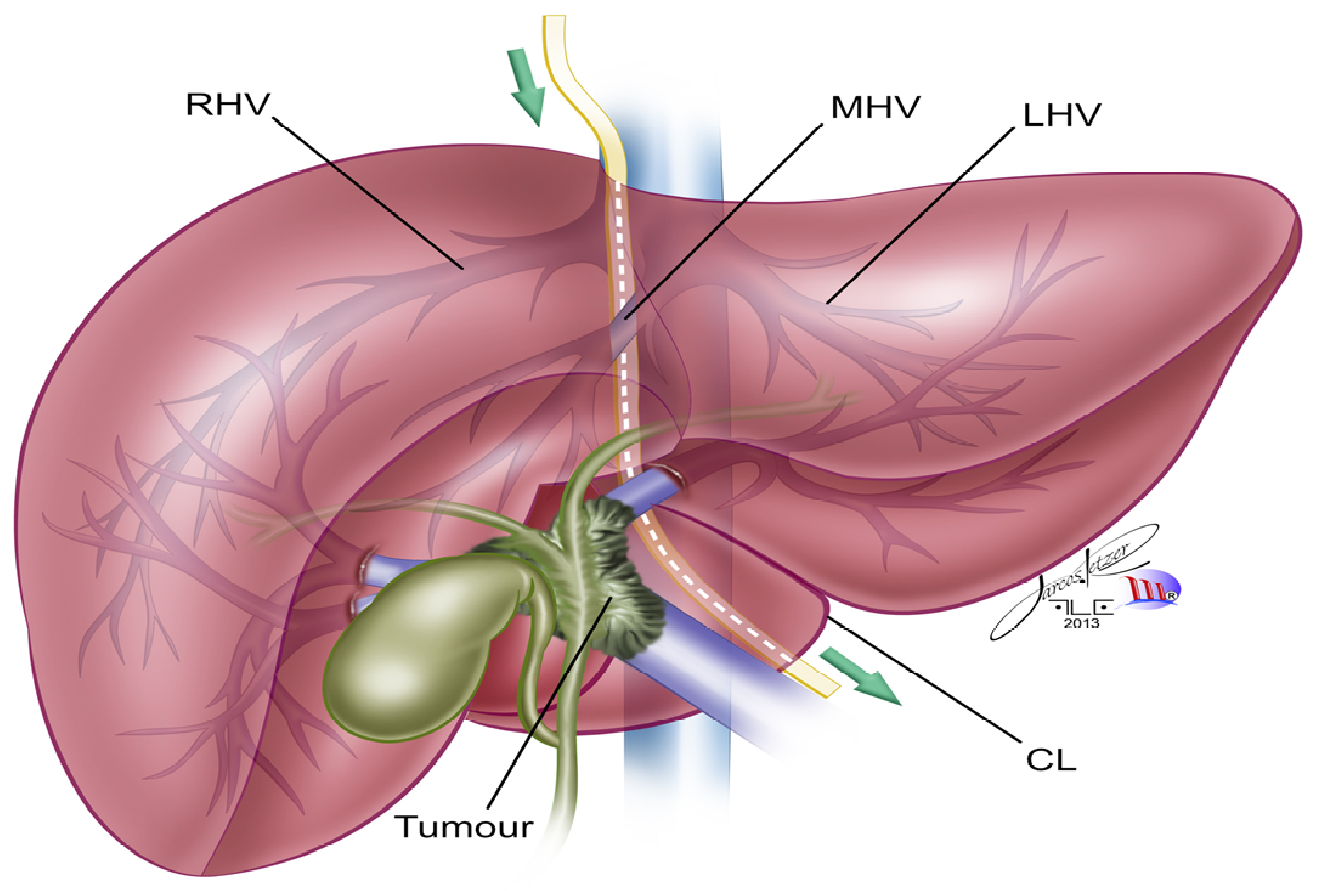

figure 1 final . 


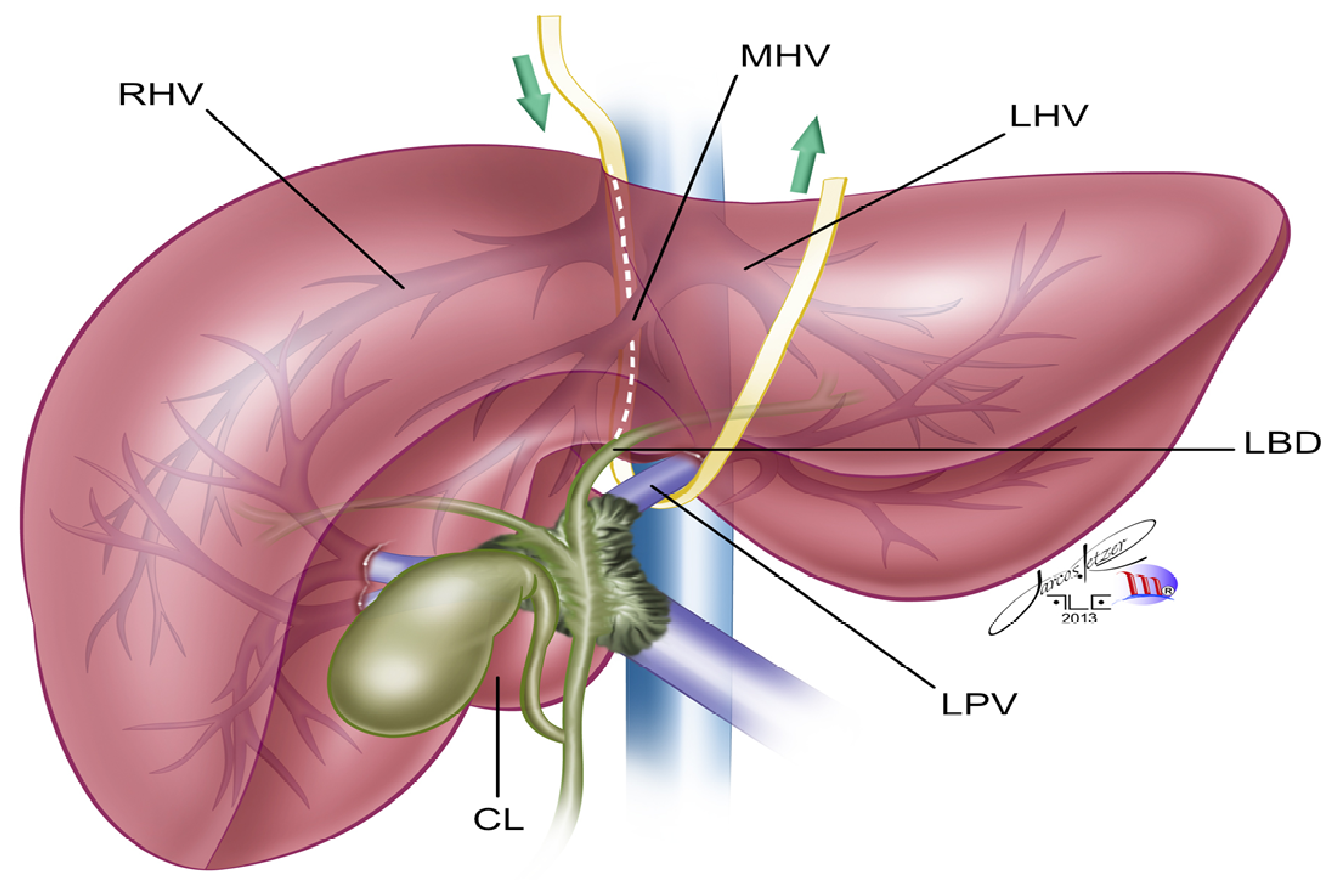

figure 2 final . 


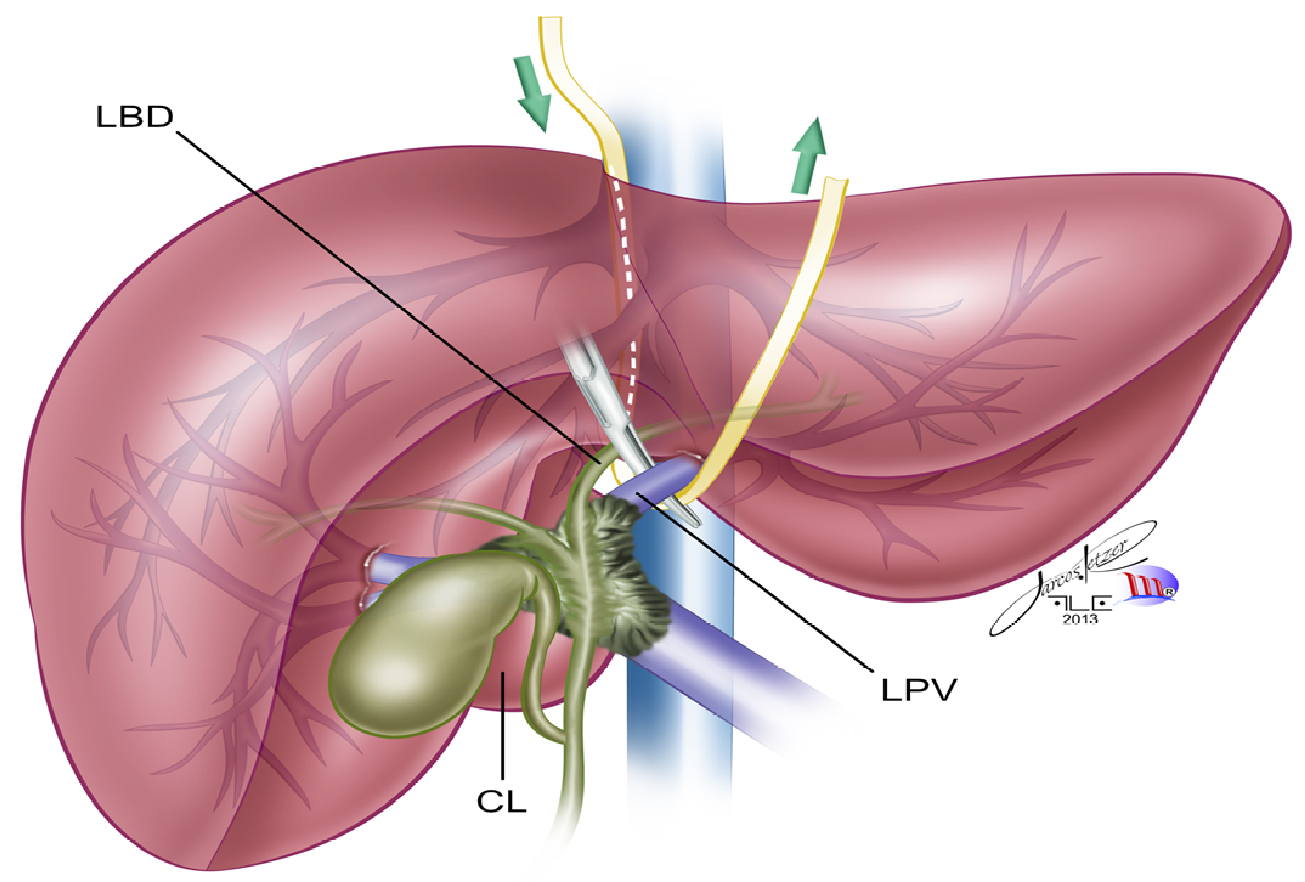

figure 3 final . 


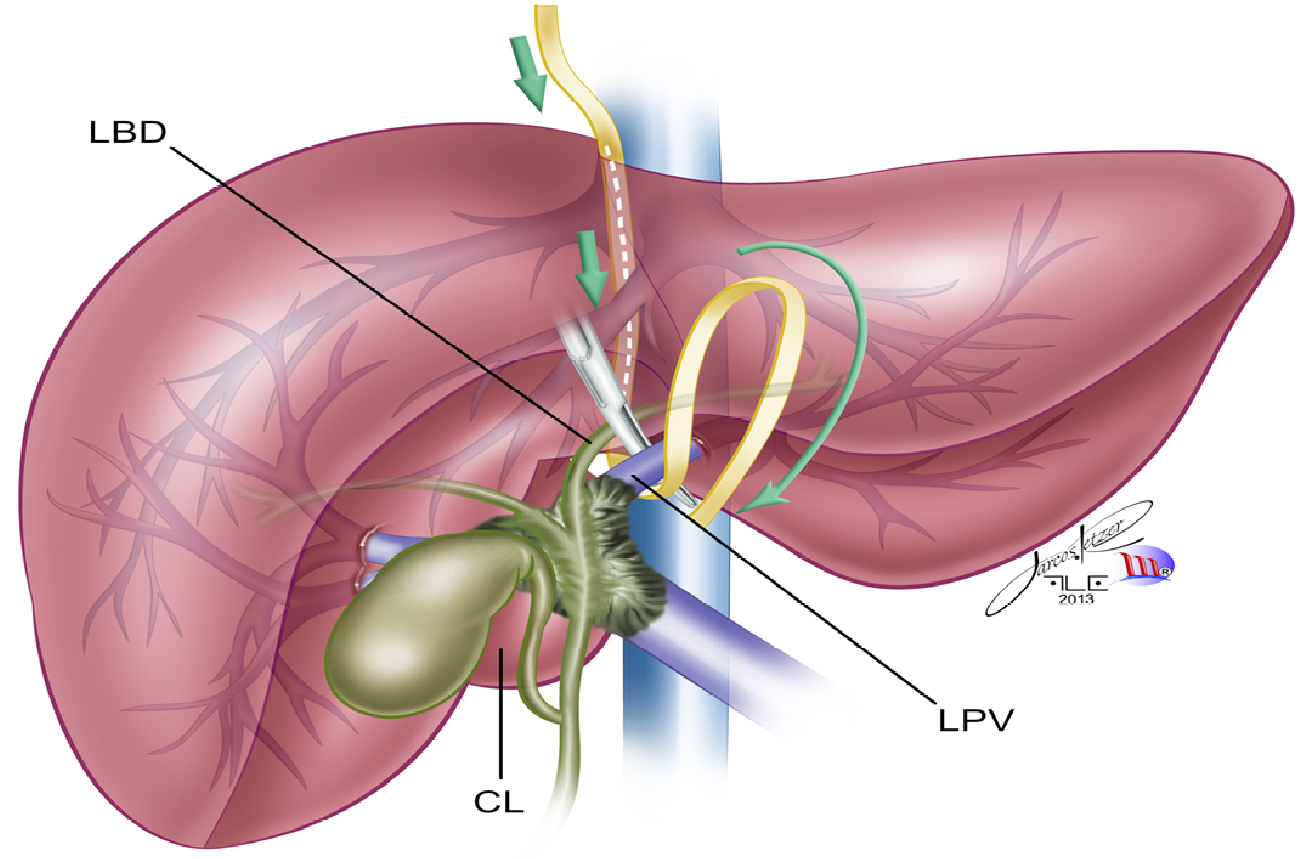

figure 4 final . 


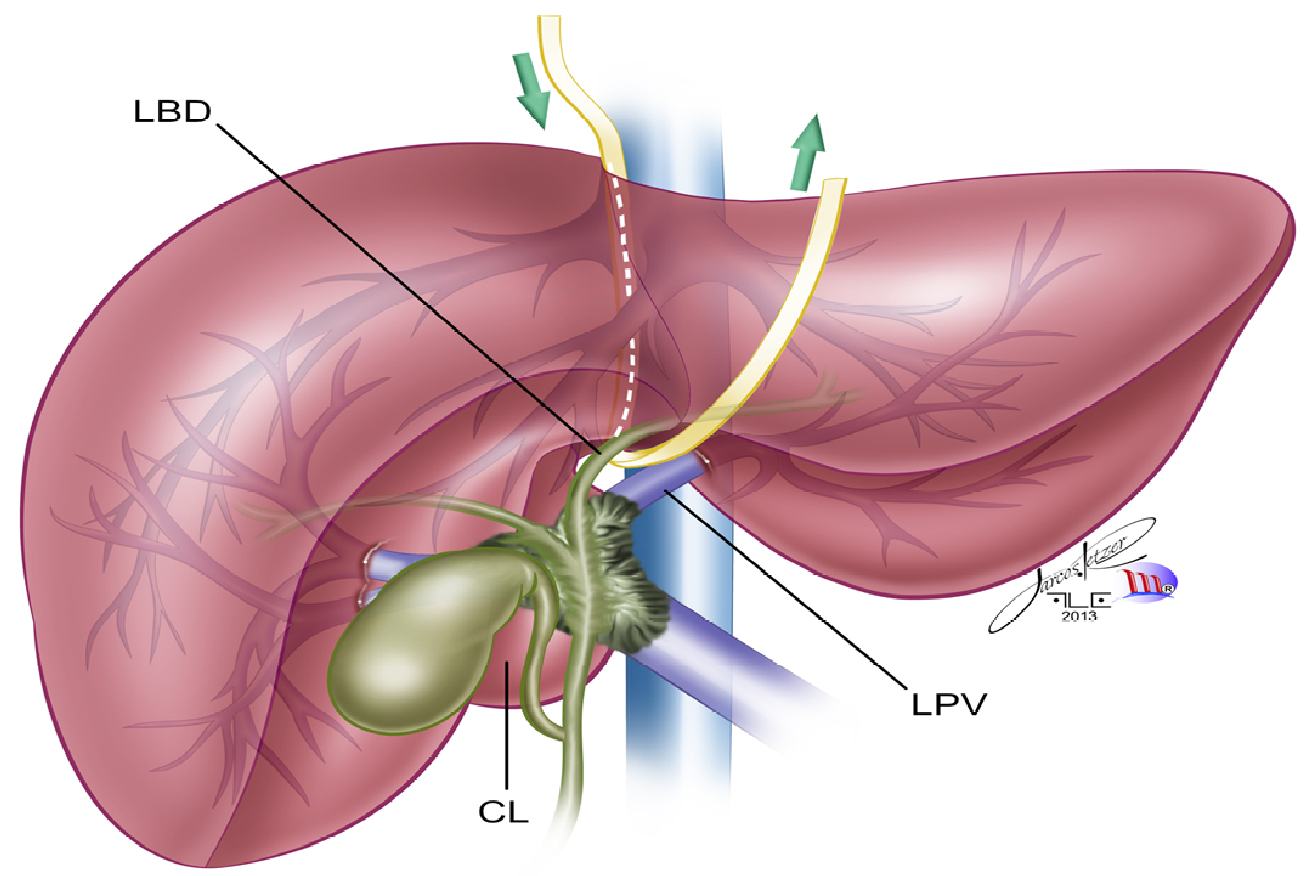

figure 5 final . 


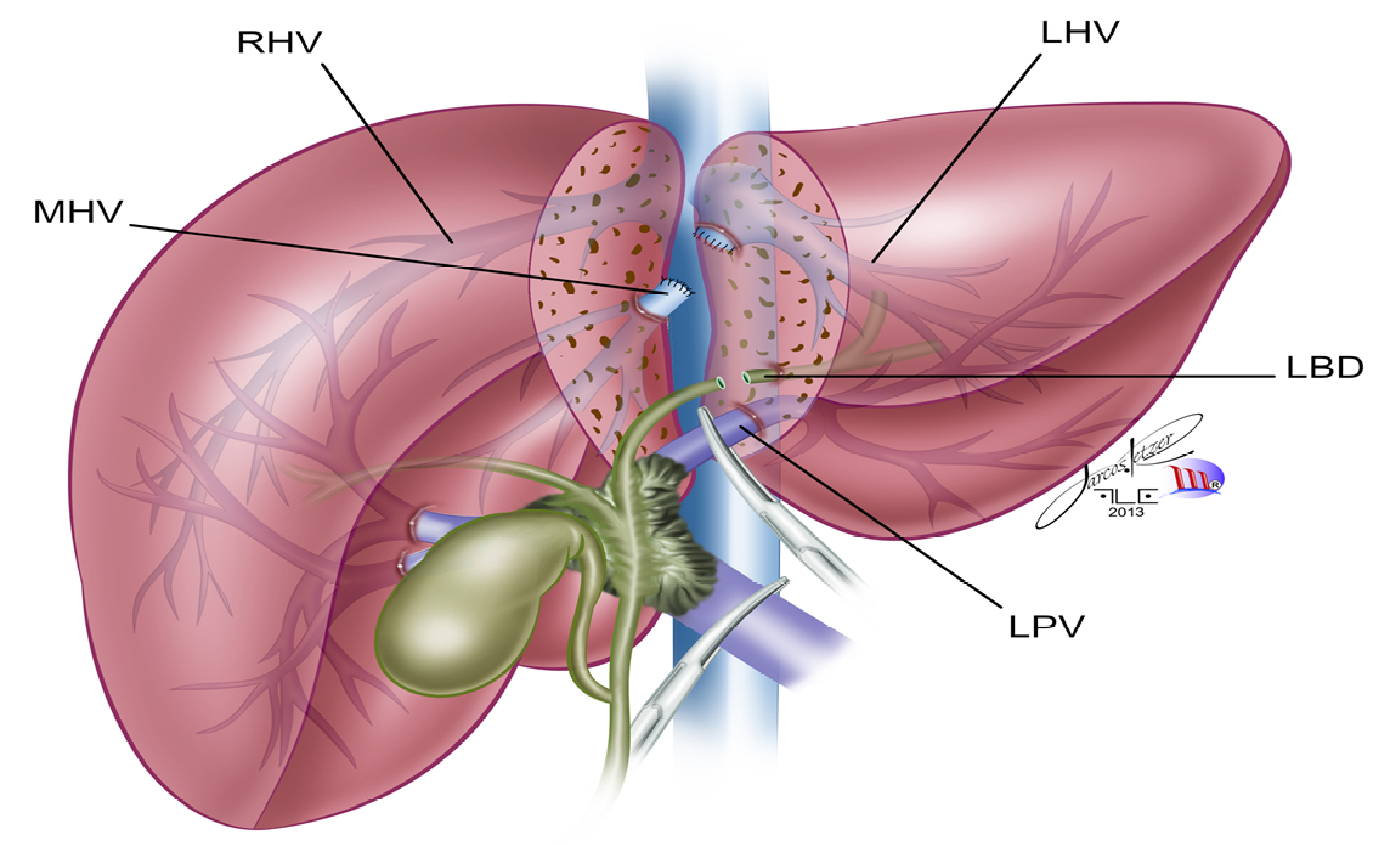

figure 6 final . 


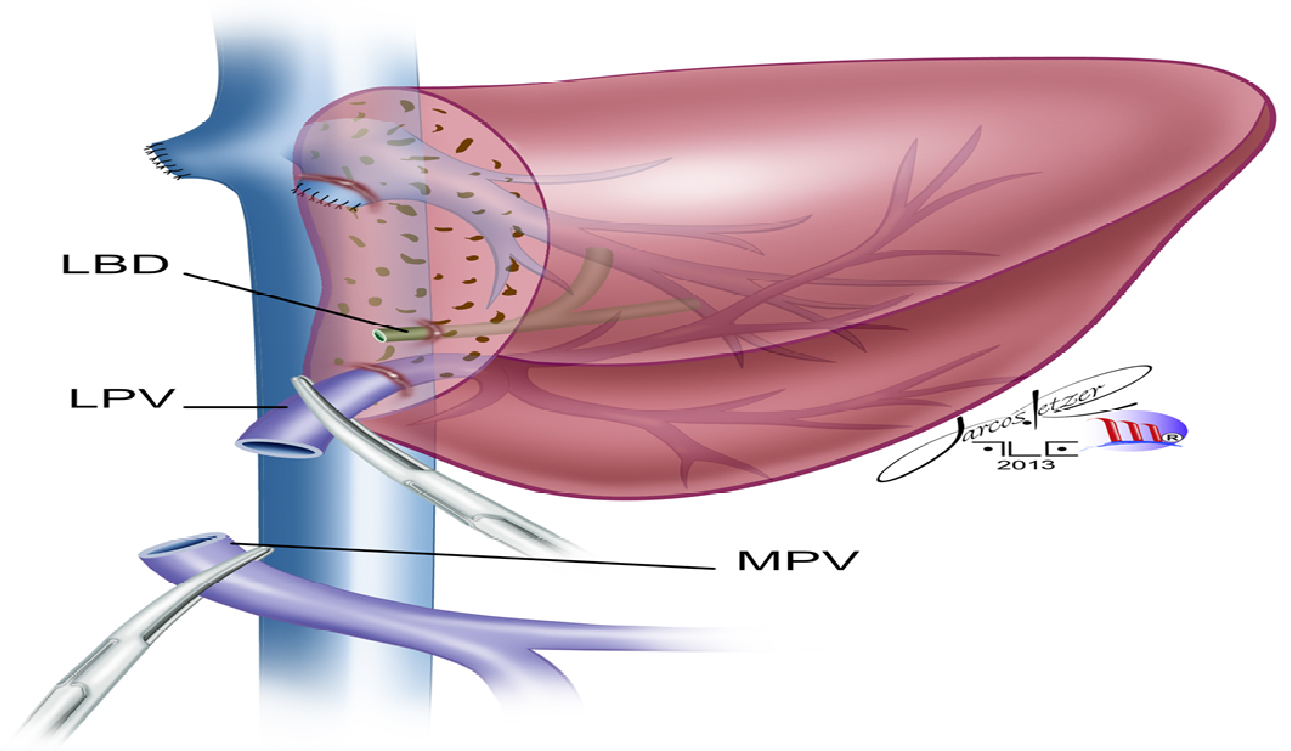

figure 7 final . 


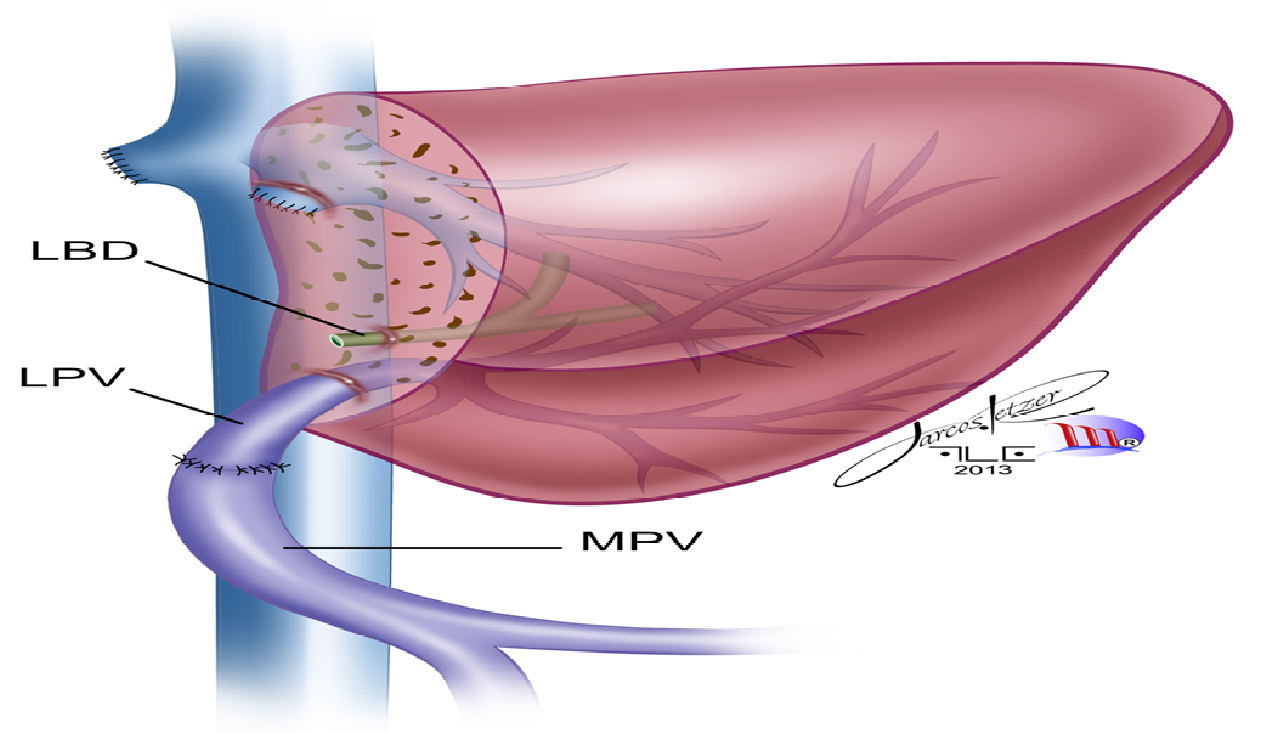

figure 8 final . 


\section{University Library}

\section{- M M I E E R VA A gateway to Melbourne's research publications}

Minerva Access is the Institutional Repository of The University of Melbourne

\section{Author/s:}

Perini, MV;Coelho, FF;Kruger, JA;Rocha, FG;Herman, P

Title:

Extended right hepatectomy with caudate lobe resection using the hilar "en bloc" resection technique with a modified hanging maneuver

\section{Date:}

2016-03-15

\section{Citation:}

Perini, M. V., Coelho, F. F., Kruger, J. A., Rocha, F. G. \& Herman, P. (2016). Extended right hepatectomy with caudate lobe resection using the hilar "en bloc" resection technique with a modified hanging maneuver. JOURNAL OF SURGICAL ONCOLOGY, 113 (4), pp.427-431. https://doi.org/10.1002/jso.24154.

Persistent Link:

http://hdl.handle.net/11343/290840 